\title{
Psychometric properties of the 7-item game addiction scale among french and German speaking adults
}

\author{
Yasser Khazaal ${ }^{1,2^{*}}$, Anne Chatton', Stephane Rothen', Sophia Achab ${ }^{1}$, Gabriel Thorens', Daniele Zullino ${ }^{1,2}$ \\ and Gerhard $\mathrm{Gmel}^{3}$
}

\begin{abstract}
Background: The 7-item Game Addiction Scale (GAS) is a used to screen for addictive game use. Both cross crosslinguistic validation and validation in French and German is needed in adult samples. The objective of the study is to assess the factorial structure of the French and German versions of the GAS among adults.

Methods: Two samples of men from French $(N=3318)$ and German $(N=2665)$ language areas of Switzerland were assessed with the GAS, the Major Depression Inventory (MDI), the Brief Sensation Seeking Scale, and the Zuckerman-Kuhlman Personality Questionnaire (ZKPQ-50-cc). They were also assessed for cannabis and alcohol use.

Results: The internal consistency of the scale was satisfactory (Cronbach $a=0.85$ ). A one-factor solution was found in both samples. Small and positive associations were found between GAS scores and the MDI, as well as the Neuroticism-Anxiety and Aggression-Hostility subscales of the ZKPQ-50-cc. A small negative association was found with the ZKPQ-50-cc Sociability subscale.
\end{abstract}

Conclusion: The GAS, in its French and German versions, is appropriate for the assessment of game addiction among adults.

Keywords: Internet addiction, Internet Gaming Disorder, Game Addiction Scale

\section{Background}

The expansion of the Internet comes with numerous benefits, including its use for commercial, social, psychological, academic, and medical purposes [1-9]. Serious concerns have been raised, however, related to possible Internet and Internet Gaming addictions [10-15]. In particular, online games have received attention for their possible links to addictive patterns of use in a subset of users [16-18]. A number of studies have reported important associations between Internet or game addictions and psychiatric constructs or disorders [19], such as depression [20-22], anxiety disorders [22, 23], attention deficit disorder [21, 24], loneliness [25-27], introversion, neuroticism, impulsivity $[17,18,26,28-31]$, and substance abuse disorders [32].

\footnotetext{
* Correspondence: yasser.khazaal@hcuge.ch

'Department of Mental health and psychiatry, Geneva University Hospitals, Geneva, Switzerland

${ }^{2}$ Department of psychiatry, Geneva University, Geneva, Switzerland Full list of author information is available at the end of the article
}

Excessive Internet use has furthermore been associated with family and social problems $[33,34]$.

Internet gaming disorder" (IGD) [35] was introduced in the section 3 of the DSM-5 as a condition warranting more clinical research and experience before it might be considered for inclusion as a formal disorder. The DSM5 suggests that IGD may refer to the persistent and recurrent use of Internet games associated with distress or impairment in a minimum 12-month period.

It was commonly reported that symptoms of Internet Gaming Disorder include persistent preoccupation with Internet Gaming, difficulty to control or cut down the time spent on games, negative consequences of loss of control (deceiving others, conflict, social isolation and fatigue, lost relationship or opportunities), loss of interest in other activities, use of the Internet gaming to escape or relieve a dysphoric mood, withdrawal and tolerance [36-38].

Since the emergence of the concept of Internet addiction [39] and Internet Gaming Disorder, a number of 
psychometric measures have been developed [37, 39-43]. The 7-item Game Addiction Scale (GAS) is one such short measure. This scale was specifically developed by Lemmens et al. to assess gaming among adolescents [44] and was conceptually based on the criteria for pathological gambling in the fourth edition of the DSM (DSM-IV). Each item on the GAS is preceded by the statement "During the last six months, how often..." and is scored on a 5 -point Likert scale $(1=$ never, $2=$ rarely, $3=$ sometimes, $4=$ often, and $5=$ very often). Lemmens et al. [44] suggested two formats for the assessment of the presence of game addiction: a monothetic format (all items scoring above 3 ) and a polythetic format (at least half of the items scoring 3 or above). He hypothesized that the monothetic format would lead to a better estimate of the prevalence of addiction than the polythetic format would [44].

Good correlations were found between GAS scores and the weekly time spent on games. The scores were furthermore correlated with a number of constructs previously associated with game addictions such as lower life satisfaction, lower social competence, higher loneliness, and higher aggression [44]. Higher GAS scores were associated with attentional bias and more errors in response inhibition related to game cues [45]. The findings are in line with numerous studies linking impulsivity and specific cue reactivity with other addictive behaviors [46-48], Internet addiction $[17,29]$ or gambling-related disorders [49]. Factorial analyses indicated that the GAS was unidimensional [44, 50]. As compared with other scales, the GAS has better coverage of the IGD criteria in the DSM-5 [35] (see also Table 1).

Surprisingly, the psychometric characteristics of the scale were not reported among young adults despite the wide dissemination of games in that population [16], particularly among young males [25].

The main goal of the present study was to investigate the psychometric properties of the 7-item GAS in young adult males. A secondary goal of the study was to perform a cross-validation of two samples from different linguistic regions in Switzerland-French- and German-speaking-and to assess the invariance or the equivalence property of the GAS across these two linguistic groups.

\section{Methods}

\section{Participants and procedure}

The data used in this study originated from a longitudinal study designed to assess substance and game use among young Swiss men: the Cohort Study on Substance Use Risk Factors (C-SURF).

The study at hand, issued from the C-SURF research protocol number $15 / 07$, was approved by the Lausanne University Medical School's Ethics Committee for Clinical Research.

All participants gave their written informed consent to participate in the study.

Participants were recruited between August 2010 and November 2011 in three of the six national army recruitment centers. One of the centers is located in Lausanne (French-speaking area) and the other two in Windisch and Mels (German-speaking area). The recruitment centers cover all Swiss French-speaking cantons and 21 of 26 cantons in Switzerland. Army conscription is mandatory in Switzerland, and so virtually all young men of the corresponding cantons who are about 20 years old were eligible for participation in the CSURF study.

During the study recruitment period, 15,074 men reported to the recruitment centers. Of these potential participants, 1,829 (12.1\%) were never informed about C-SURF (brief illness at the appointment time, not informed about the study by the military staff), or were randomly selected into another ongoing study, called $\mathrm{CH}-\mathrm{X}$ [51]. $\mathrm{CH}-\mathrm{X}$ is a repeated cross-sectional survey, which has a fixed and mandatory schedule of $90 \mathrm{~min}$ within the recruitment procedures. Hence, commonly

Table 1 GAS and its concordance with the DSM-5 proposed criteria for Internet gaming disorder

\begin{tabular}{|c|c|c|}
\hline & How often in the last six months... & $\begin{array}{l}\text { Internet gaming disorder: proposed criteria } \\
(\mathrm{DSM}-5)^{\mathrm{a}}\end{array}$ \\
\hline Item 1 & Have you thought all day long about playing a game? & Preoccupation (item 1) \\
\hline Item 2 & Have you played longer than intended? & Withdrawal (item 5) \\
\hline Item 3 & Have you played games to forget about real life? & Tolerance (item 2) \\
\hline Item 4 & Have others unsuccessfully tried to reduce your time spent on games? & Unsuccessful attempts to reduce or stop (item 4) \\
\hline Item 5 & Have you felt upset when you were unable to play? & Loss of interests in other activities (7) \\
\hline Item 6 & $\begin{array}{l}\text { Have you had arguments with others (e.g. family, friends) } \\
\text { over your time spent on games? }\end{array}$ & Continue despite problems (item 7) \\
\hline \multirow[t]{3}{*}{ Item 7} & \multirow[t]{3}{*}{ Have you neglected important activities (e.g. school, work, sports) to play games? } & Deceived others (item 6) \\
\hline & & Escape (item 3) \\
\hline & & Lost relationships or opportunities \\
\hline
\end{tabular}

The suggested GAS items for each criteria are shown in parentheses. Number of criteria: 5 or more. Time criteria: 12 months 
participation in $\mathrm{CH}-\mathrm{X}$ did not interfere with our enrolment procedures, which took place before the start of army procedures. However, in few cases participants were already gone to fill in $\mathrm{CH}-\mathrm{X}$ questionnaires before we could inform them about our study. As we have promised not to interfere with army procedures, we were not able to contact some of them. To the best of our knowledge, we cannot see any systematic biases that these few non-contacted people due to $\mathrm{CH}-\mathrm{X}$ requirements may have caused. These men did not report to the research staff and could not be included. Of the $13,245(87.9 \%)$ men who were informed about the study, 7,563 (57.1\%) gave their written consent to participate. Unfortunately, we have no information on the motives for not consenting. One reason may be that signing a kind of contract for a long-lasting study (CSURF is planned for a period of 10 years) may deter some individuals. A comparison of consenters and nonconsenters [52] revealed that non-consenters were more often substance users than consenters, but differences were often non-significant and sometimes in opposite direction (e.g. consenters were more often alcohol users than non-consenters). Recruitment centers were used only to enroll participants; questionnaires were sent to private addresses and confidentiality was assured, particularly regarding the army. A final total of 5,990 (79.2\%) participants completed the baseline questionnaire. Of this number, 3,320 were French speaking and 2,670 were German speaking.

\section{Instruments}

\section{Game addiction scale (GAS)}

The English version of the scale was translated and backtranslated to French and German. An introductory statement for the scale items clearly directed participants to answer in relation to their game use: "Now we are interested to know how much time you have spent on games. This includes cybergames on internet or games on a console" (Additional file 1).

In accordance with the hypothesis of Lemmens et al. [44], those who scored "sometimes" or more on all seven items were defined as monothetic gamers ("pathological gaming"), and those who scored "sometimes" or more on at least half of the items (four to six of seven items) were defined as polythetic gamers (excessive gaming).

High reliabilities for the Game addiction scale with Cronbach alpha of .82 to .87 were reported in the original validation study [44].

\section{Major depression inventory (MDI)}

The MDI was used to determine the level of depression in the past two weeks [53, 54]. It is a self-report mood questionnaire. A six-point scale from "never" (0) to "all the time" (5) was used, and a total score was computed.
The MDI can also be used as a diagnostic instrument with algorithms leading to the DSM-IV or to the International Classification of Mental and Behavioral Disorders (ICD-10) categories of no depression, mild to moderate depression, and severe depression.

Previous studies on the Major Depression Inventory indicate that MDI has good reliability and internal consistency (Cronbach's alpha coefficient: up to 0.94) as well as good sensitivity, specificity, and validity as a unidimentional depression severity scale with adequate cutoff scores $[53,55,56]$.

\section{Brief sensation seeking scale (BSSS)}

The BSSS [57] is an eight-item scale, each item scored on a five-point scale from "strongly disagree" (1) to "strongly agree" (5). The BSSS involves the following dimensions: adventure, boredom, disinhibition, and experience seeking. The total score was previously associated with a risk of drug use in a sample of adolescents [57].

Adequate internal consistency of the BSSS was previously reported (Cronbach's alpha coefficient: 0.74) [57].

\section{The Zuckerman-Kuhlman personality questionnaire (ZKPQ-50-CC)}

The ZKPQ-50-cc assesses different aspects of personality [58]. Three subscales, each consisting of 10 items, were used to assess neuroticism/anxiety, sociability, and aggression/hostility. The participants indicated whether they agreed or disagreed with each statement. A mean score was computed for each subscale. Other studies have shown a contribution of neuroticism/anxiety and aggression/hostility to Internet addiction [59]. The ZKPQ-50-cc showed satisfactory psychometric and cross-cultural properties, including adequate reliability across subscales and countries (Cronbach's alpha coefficient up to 0.70) [58].

\section{Questionnaires on substance use}

Alcohol use was assessed in a 12-month time frame (Table 2). Accordingly, the frequency of binge drinking (six standard drinks or more on one occasion) and of drinking days during the week (Monday to Thursday) was calculated. Age of onset of drunkenness (first episode of being drunk) was also assessed according to the European School Survey Project on Alcohol and Other Drugs [60]. Cannabis use was assessed by asking about the following: age of cannabis use onset, age of first "high" on cannabis, and cannabis use and frequency of use during the past 12 months.

\section{Statistical analyses}

In this study, we used SPSS 18.0 and AMOS 19.0 (Analysis of Moment Structures; SPSS Inc., Chicago, IL) software programs. First, descriptive statistics were computed for the participants' characteristics. Internal consistency, that is, the 
Table 2 Participants' characteristics

\begin{tabular}{|c|c|c|}
\hline & $\begin{array}{l}\text { French-speaking } \\
\text { community } \\
(N=3,318)\end{array}$ & $\begin{array}{l}\text { German-speaking } \\
\text { community } \\
(N=2,665)\end{array}$ \\
\hline Age & $20.3(1.3)$ & $19.7(1.1)$ \\
\hline Age first drunk & $15.6(1.8)$ & $15.4(1.7)$ \\
\hline \multicolumn{3}{|l|}{$\begin{array}{l}\text { Frequency six standard drinks or } \\
\text { more (binge) on one occasion in } \\
\text { the past } 12 \text { months }\end{array}$} \\
\hline - Never & 23.8 & 17.8 \\
\hline - Less than monthly & 31.4 & 34.7 \\
\hline - Once a month or more & 44.8 & 47.5 \\
\hline $\begin{array}{l}\text { Frequency of drinking during the } \\
\text { week (Monday to Thursday) in } \\
\text { days per week in the past } \\
12 \text { months }\end{array}$ & $27.3(42.4)$ & $26.2(41.7)$ \\
\hline Age cannabis use onset & $15.9(2.0)$ & $15.6(1.9)$ \\
\hline $\begin{array}{l}\text { Age you got "high" on cannabis } \\
\text { for the first time }\end{array}$ & $15.9(2.0)$ & $15.7(1.8)$ \\
\hline \multicolumn{3}{|l|}{ Cannabis use last 12 months } \\
\hline - Yes & 32.0 & 28.9 \\
\hline$-\mathrm{No}$ & 68.0 & 71.1 \\
\hline \multicolumn{3}{|l|}{$\begin{array}{l}\text { Cannabis frequency of use last } \\
12 \text { months }\end{array}$} \\
\hline - Once a month or less & 16.7 & 16.3 \\
\hline - Once to 3 times per week & 7.7 & 7.3 \\
\hline $\begin{array}{l}\text { - } 4 \text { to } 5 \text { times per week } \\
\text { or more often }\end{array}$ & 7.6 & 5.3 \\
\hline - Never & 68.0 & 71.1 \\
\hline \multicolumn{3}{|l|}{ Gaming use classification } \\
\hline - Monothetic & 2.3 & 2.3 \\
\hline - Polythetic & 10.6 & 8.1 \\
\hline - $\quad$ Non-problematic game users & 87.1 & 89.6 \\
\hline \multicolumn{3}{|l|}{ Major Depression Inventory } \\
\hline - No depression & 93.3 & 94.5 \\
\hline - Mild to moderate depression & 4.1 & 3.5 \\
\hline - Severe depression & 2.6 & 1.8 \\
\hline \multicolumn{3}{|l|}{$\begin{array}{l}\text { Brief Sensation Seeking } \\
\text { (BSSS total scale) }\end{array}$} \\
\hline - Adventure subscale & $2.9(0.9)$ & $3.2(0.9)$ \\
\hline - Boredom subscale & $2.8(1.2)$ & $3.1(1.2)$ \\
\hline - Disinhibition subscale & $2.7(1.0)$ & $3.1(1.0)$ \\
\hline - Experience seeking subscale & $2.9(1.1)$ & $3.0(1.1)$ \\
\hline Personality ZKPQ-50-cc & $3.2(1.2)$ & $3.6(1.1)$ \\
\hline - Aggression/hostility subscale & $4.3(2.3)$ & $4.0(2.1)$ \\
\hline - Anxiety subscale & $2.1(2.1)$ & $1.9(1.9)$ \\
\hline - Sociability subscale & $5.9(2.3)$ & $5.9(2.1)$ \\
\hline
\end{tabular}

Data are expressed as mean and standard deviation (M [SD]) or as a percentage depending on their quantitative or categorical nature extent to which the GAS items were interrelated, was then measured by using Cronbach's coefficient. Streiner and Norman [61] suggest that alpha be above 0.70 , but not much higher than 0.90 .

Next, exploratory factor analyses (EFAs) were used to assess factor stability of the scale as validated by Lemmens and al [44]. The number of factors were extracted with Velicer's minimum average partial (MAP) test performed on the correlation matrix [62]. This number was then confirmed through parallel analyses. In parallel analyses, the focus is on the number of components that account for more variance than the components derived from random data, whereas in the MAP test, the focus is on the relative amounts of systematic and unsystematic variance remaining in a correlation matrix after extractions of an increasing number of components [63].

Although EFA is more appropriate for newly designed questionnaires, it is not uncommon to also use it in a revalidation process when data are collected from another sample or another population. The use of EFA here was to evaluate the stability of the factors in the two linguistic regions, as this is a basic prerequisite for further investigation of the equivalence of the tool among the different subgroups.

For the determination of multigroup invariance, we used the procedure described in the structural equation modeling (SEM) following the work of Jöreskog [64]. In testing for group equivalence, it is customary to use confirmatory factor analysis (CFA) models, a method among the general class of SEM. Depending on the research question, searching for group equivalence may imply a series of tests performed in the following restrictive order: configural equivalence, measurement equivalence, and structural equivalence. Configural invariance testing focuses on the extent to which the number of factors and patterns of their structure are similar between groups. Worth noting, however, is that determination of an appropriate baseline model is required for each group separately, upon which the configural model is derived. On the other hand, in testing for measurement and structural invariance, interest focuses more specifically on the extent to which parameters in the measurement and structural components of the model are equivalent across the groups $[65,66]$. Given that our research questions concern measurement equivalence across groups, the statistical analyses focus on configural invariance and invariance of factor loadings across the two linguistic regions.

\section{Evaluation of model fit}

Goodness of fit of the models is examined through various indices, as described below [67].

a. The $\chi^{2}$ to degrees of freedom ratio $\left(\chi^{2} / \mathrm{df}\right)$. Several researchers have recommended the use of this ratio as a measure of fit to overcome problems associated 
with the $\chi^{2}$ test statistic. These problems include, among others, violation of assumptions, model complexity, and dependence on sample size. Ratios as low as 2 seem to indicate a reasonable fit.

b. The comparative fit index (CFI). The CFI ranges from 0 to 1 , with higher values indicating better fit. A rule of thumb is that values greater than 0.95 may be interpreted as a good fit, whereas values between 0.90 and 0.95 are indicative of acceptable fit relative to the independence model.

c. The root mean square error of approximation (RMSEA). This is a measure of approximate fit in the population and is therefore concerned with the discrepancy due to approximation. The RMSEA is bounded below 0. RMSEA values less than or equal to 0.05 can be considered as a good fit, between 0.05 and 0.08 an acceptable fit, and greater than $0.8 \mathrm{a}$ mediocre fit, whereas values $>0.10$ are not acceptable.

Changes in goodness-of-fit statistics were also examined to detect differences in the different models. A significant difference in $\chi^{2}$ values between nested models means that all equality constraints do not hold across the groups.

Graphical representation of the GAS items measured on an ordinal scale shows that normality assumption is not tenable. As a consequence, asymptotically distributionfree estimation instead of maximum likelihood estimation is a good strategy to accommodate non-normally distributed data in SEM analyses.

Lastly, concurrent validity was investigated by correlating the total GAS score with the scores of the MDI [53]; the BSSS [57]; and the Neuroticism-Anxiety, Sociability, and Aggression-Hostility subscales of the ZKPQ-50-cc [58]. We also examined the strength of the association of the scale with other measures related to alcohol and cannabis use. According to Cohen's rule of thumb, any correlation greater than 0.5 is large, from $0.5-0.3$ is moderate, from $03-0.1$ is small, and less than 0.1 is trivial [68].

\section{Missing values}

GAS missing values were handled with the hot deck imputation method, in which each missing value is replaced with an observed response from a similar unit with respect to the characteristics observed by both cases [69]. In our study, the BSSS was chosen as the "deck variable," as it includes little to no missing data [70]. We used a hot deck imputation macro for SPSS users by $\mathrm{T}$. van der Weegen, which can be downloaded from the following website: http://www.spsstools.net/SampleSyntax.htm.

\section{Sample size considerations}

Sample size plays an important role in providing unbiased parameter estimates and accurate model fit information.
Following Bentler and Chou [71], who recommended at least a 5:1 ratio of subjects to variables for normal and elliptical distributions, there seems to be a general consensus among researchers for the adoption of this ratio. However, for categorical or non-normally distributed variables, as is the case here, larger samples are required than for continuous or normally distributed variables. A ratio of at least 10 subjects per variable for this type of distribution is recommended [72]. The sample in the present study fulfills this requirement.

\section{Results}

Of the original 5,990 observations initially recorded, GAS data were missing for 42 participants $(0.7 \%)$. The use of hot deck imputation successfully imputed data for 35 of them, still leaving 7 cases incomplete. A final sample size of 5,983 respondents (3,318, French-speaking and 2,665 German-speaking) was then analyzed. Participants' mean age was 20.0 years $(S D=1.2)$. Of this final sample, $10.6 \%$ of the French and $8.1 \%$ of the German respondents were classified as polythetic users, whereas $2.3 \%$ of respondents in each group were classified as monothetic users. The characteristics of each linguistic region are reported in Table 2.

\section{French-speaking community}

The internal consistency of the GAS was good, as reflected by a Cronbach's coefficient of 0.86 . EFA by Velicer's MAP test suggested a one-factor solution. This finding was successfully confirmed by parallel analysis. This one-factor model was then evaluated in CFA with AMOS. Guided by modification indices and unusual standardized residuals that suggested the correlation of six error variances, we established a well-fitted model that exhibited good fit relative to the independence model $\left(\chi^{2} / \mathrm{df}=2.6, \mathrm{CFI}=0.99\right.$, $\left.\mathrm{RMSEA}=0.02\right)$.

\section{German-speaking community}

The internal consistency of the scale was satisfactory (Cronbach $\alpha=0.85)$. A one-factor solution was also found in EFA by Velicer's MAP and was confirmed by parallel analysis. The same path model used to evaluate the French-speaking group was applied to the Germanspeaking group. This model performed more poorly but still gave acceptable goodness-of-fit values $\left(\chi^{2} / \mathrm{df}=5.9\right.$, CFI $=0.94$, RMSEA $=0.04$ ).

\section{Multigroup analysis \\ Testing for configural equivalence}

Having determined a well-fitting model for each group separately, we tested configural equivalence in which the same parameters were estimated again in a multigroup model. In other words, parameters were estimated for both groups at the same time. Results related to this multigroup model 
revealed a $\chi^{2}$ value of 91.53 with 17 degrees of freedom. The CFI and RMSEA values were 0.97 and 0.02 , respectively, providing an acceptable fit. These values are the baseline values against which all subsequent tests for invariance were compared.

\section{Testing for factorial measurement equivalence}

A model with all loadings (factor loadings by group are displayed in Table 3) constrained to be equal across groups was fitted. Goodness-of-fit statistics related to this constrained two-group model are presented in Table 4 (second entry). In testing for the invariance of this constrained model, we compared its $\chi^{2}$ value of 114.59 with 23 degrees of freedom with that for the unconstrained model $\left(\chi_{(17)}^{2}=91.53\right)$. This comparison yielded a $\chi^{2}$ difference $\left(\Delta \chi^{2}\right)$ of 23.06 with 6 degrees of freedom, which is statistically significant $(p=0.001)$. Hence, the equality constraints for all factor loadings were rejected. Given the rejection of full factorial invariance, we proceeded to check which factors loading were different. As factor-loading parameters were found to be invariant across groups, their specified equality constraints were maintained, cumulatively, throughout the remainder of the invariance-testing process [73]. First, constraining factor loadings of the Tolerance item to be equal across groups yielded non-significant results, suggesting they are equal. For identification purposes, loading for the Salience item was already constrained to take the value of 1 in both groups. Next, holding this equality constraint and adding the equality constraint for Mood Modification still resulted in non-significant $\chi^{2}$ values. This continued until we reached Withdrawal, where significant $\chi^{2}$ results suggested non-equality between the two groups. Tests were repeated for Conflict and Problems, which were again non-significant. The detailed procedure is shown in Table 4. All observed measures

Table 3 Factor loadings and goodness-of-fit measures

\begin{tabular}{llll}
\hline & & \multicolumn{2}{l}{ Factor loading } \\
\cline { 3 - 4 } & & French-speaking & German-speaking \\
\hline Item 1 & Salience & 0.65 & 0.62 \\
Item 2 & Tolerance & 0.65 & 0.65 \\
Item 3 & Mood modification & 0.73 & 0.72 \\
Item 4 & Relapse & 0.73 & 0.71 \\
Item 5 & Withdrawal & 0.65 & 0.71 \\
Item 6 & Conflict & 0.64 & 0.62 \\
Item 7 & Problems & 0.65 & 0.61 \\
Cronbach a & & 0.86 & 0.85 \\
$X^{2} /$ df & & 2.6 & 5.9 \\
RMSEA & & 0.02 & 0.04 \\
CFI & & 0.99 & 0.94 \\
\hline
\end{tabular}

except for Withdrawal were found to be operating equivalently for both linguistic regions.

\section{Correlation analysis in the French-speaking community}

Correlation analysis was used to explore concurrent validity between GAS and other similar constructs. As shown in Table 5, the association of GAS with the MDI total score and with the ZKPQ-50-cc Anxiety subscale was small ( $\rho=0.27$ and $\rho=0.24$, respectively) and the association of GAS with the ZKPQ-50-cc Sociability subscale was small and negative $(\rho=-0.20)$. The correlations with the other assessment measures were considered trivial.

\section{Correlation analysis in the German-speaking community}

As shown in Table 6, the association of GAS with MDI and with the ZKPQ-50-cc Anxiety subscale was small $(\rho=0.24$ and $\rho=0.23)$. This association was smaller with the ZKPQ-50-cc Aggressivity subscale $(\rho=0.15)$ and with the Sociability subscale $(\rho=-0.10)$.

\section{Discussion}

The present study is the first to assess, to our knowledge, the psychometric characteristics of the 7-item GAS among representative samples of French- and German-speaking adult men.

The main finding is that the one-factor model of the 7-item GAS has good psychometric properties and fits the data well in both samples. The results are in accordance with a number of previous findings $[44,50]$ and allow their extension to adults. [74, 75].

Furthermore, all observed measures except for Withdrawal were found to be operating equivalently for both linguistic regions. This adds to the cross-linguistic validity of the scale. The weakness related to the Withdrawalrelated item may be due to lack of precision of this concept when applied to game use [36]. It may also indicate cross-group differences in the underlying construct. This hypothesis does not hold, however, because these differences are not reflected in the magnitude of the factor loadings, whose values are similar (0.65 vs. 0.71$)$. Discrepancies between the French and the German translation of this related item may explain this difference. However, after discussing this again with bilingual individuals, we cannot find major discrepancies in the meaning of the words used. Although this is the largest difference in factor loadings, it remains marginal compared with the others (0.06 in absolute value). Hence, the only plausible explanation is that the statistical significance of the $\chi^{2}$ statistics observed is in all likelihood induced by the large sample size of almost 6,000 individuals.

In concordance with numerous studies on game and Internet use $[19,21,76]$, an association was found between depressive symptoms and GAS scores. In 
Table 4 Summary of goodness-of-fit statistics for tests of invariance across linguistic groups

\begin{tabular}{|c|c|c|c|c|c|}
\hline Model Description & $x^{2}$ & $d f$ & $\Delta x^{2}$ & $\Delta \mathrm{df}$ & Statistical significance \\
\hline 1. Unconstrained model & 91.53 & 17 & - & - & - \\
\hline 2. All factor loadings constrained equally across groups & 114.59 & 23 & 23.06 & 6 & $p=0.001$ \\
\hline Model 2.1 & 91.92 & 18 & 0.39 & 1 & $p=0.5$ \\
\hline Model 2.2 & 92.10 & 19 & 0.56 & 2 & $p=0.8$ \\
\hline Model 2.3 & 95.85 & 20 & 4.32 & 3 & $p=0.2$ \\
\hline Model 2.4 & 105.52 & 21 & 13.99 & 4 & $p=0.007$ \\
\hline Model 2.5 & 95.90 & 21 & 4.37 & 4 & $p=0.4$ \\
\hline Model 2.6 & 99.37 & 22 & 7.84 & 5 & $p=0.2$ \\
\hline
\end{tabular}

Model 2.1: Tolerance loadings equal between French and German-speaking groups

Model 2.2: Tolerance and Mood Modification loadings equal

Model 2.3: Tolerance, Mood Modification and Relapse loadings equal

Model 2.4: Tolerance, Mood Modification, Relapse and Withdrawal loadings equal

Model 2.5: Tolerance, Mood Modification, Relapse and Conflict loadings equal

Model 2.6: Tolerance, Mood Modification, Relapse, Conflict and Problems loadings equal

addition, a small association was found between GAS scores and both the Neuroticism-Anxiety dimension and the Aggression-Hostility subscale of the ZKPQ-50-cc. These associations are in line with findings related to substance use-related addictions [77, 78] and are in concordance with other studies related to Internet or game addiction [59, 79]. Moreover, as in other studies [79], a negative association was found with the Sociability subscale. This seems to be consistent with the findings of other studies that showed an association between loneliness and low social competence with game addiction $[25,80]$.

The present study did not show an association between GAS scores and sensation seeking. This finding contradicts that of other studies [81]. Some researchers have shown that sensation seeking is related to extraversion [58]. However, game and Internet addictions seem to be more linked to introversion than to extraversion [82], and so it is plausible that sensation seeking was not associated here with the GAS scores. Similarly, in contradiction to the findings of a number of previous studies [19, 26, 32, 83], the present study failed to show an association with alcohol or cannabis use. These associations were possibly mediated by the specific preferred online activity and may differ from one activity to another [84].

With an overall $2.3 \%$ of participants classified as monothetic users and an additional $9.5 \%$ classified as polythetical users (excessive users), the prevalence rates in this study are comparable with those found in the initial GAS study [44] and in a number of other Swiss and European studies [85-89]. Slightly lower [90, 91] or higher prevalence figures [12, 92] were, however, reported in other studies. The differences are probably a

Table 5 Correlation between GAS and other constructs in the French-speaking community (among Fra)

\begin{tabular}{|c|c|c|c|c|c|c|c|c|c|c|c|c|c|c|}
\hline & 1 & 2 & 3 & 4 & 5 & 6 & 7 & 8 & 9 & 10 & 11 & 12 & 13 & 14 \\
\hline 1. GAS & 1.00 & & & & & & & & & & & & & \\
\hline 2. $\mathrm{MDI}$ & 0.27 & 1.00 & & & & & & & & & & & & \\
\hline 3. BSSS (full scale) & 0.01 & 0.09 & 1.00 & & & & & & & & & & & \\
\hline 4. Experience seeking (subscale) & 0.04 & 0.10 & 0.79 & 1.00 & & & & & & & & & & \\
\hline 5. Boredom (subscale) & -0.03 & 0.11 & 0.78 & 0.54 & 1.00 & & & & & & & & & \\
\hline 6. Adventure (subscale) & -0.02 & 0.001 & 0.77 & 0.43 & 0.42 & 1.00 & & & & & & & & \\
\hline 7. Disinhibition (subscale) & 0.05 & 0.08 & 0.79 & 0.48 & 0.51 & 0.50 & 1.00 & & & & & & & \\
\hline 8. Aggressivity ZKPQ-50-cc & 0.09 & 0.14 & 0.21 & 0.07 & 0.18 & 0.16 & 0.25 & 1.00 & & & & & & \\
\hline 9. Sociability ZKPQ-50-cc & -0.20 & -0.18 & 0.13 & -0.01 & 0.10 & 0.10 & 0.22 & 0.03 & 1.00 & & & & & \\
\hline 10. Anxiety ZKPQ-50-cc & 0.24 & 0.46 & 0.02 & 0.05 & 0.08 & -0.09 & 0.01 & 0.15 & -0.25 & 1.00 & & & & \\
\hline 11. Binge: 6 alcoholic beverages at one sitting & 0.01 & -0.08 & -0.33 & -0.18 & -0.22 & -0.17 & -0.46 & .0 .16 & -0.21 & -0.01 & 1.00 & & & \\
\hline 12. Frequency of drinking in days per week & -0.05 & 0.05 & 0.24 & 0.14 & 0.19 & 0.11 & 0.31 & 0.12 & 0.13 & 0.02 & -0.61 & 1.00 & & \\
\hline 13. Age cannabis use onset & 0.07 & -0.06 & -0.20 & -0.13 & -0.15 & -0.14 & -0.18 & -0.08 & 0.01 & -0.02 & 0.11 & -0.9 & 1.00 & \\
\hline $\begin{array}{l}\text { 14. Age getting "high" on cannabis for the first } \\
\text { time }\end{array}$ & 0.06 & -0.06 & -0.18 & -0.11 & -0.15 & -0.13 & -0.17 & -0.09 & 0.01 & -0.02 & 0.08 & -0.9 & 0.93 & 1.00 \\
\hline
\end{tabular}


Table 6 Correlation between GAS and other constructs in the German-speaking community

\begin{tabular}{|c|c|c|c|c|c|c|c|c|c|c|c|c|c|c|}
\hline & 1 & 2 & 3 & 4 & 5 & 6 & 7 & 8 & 9 & 10 & 11 & 12 & 13 & 14 \\
\hline 1. GAS & 1.00 & & & & & & & & & & & & & \\
\hline 2. $\mathrm{MDI}$ & 0.24 & 1.00 & & & & & & & & & & & & \\
\hline 3. BSSS (full scale) & 0.01 & 0.02 & 1.00 & & & & & & & & & & & \\
\hline 4. Experience seeking (subscale) & -0.02 & 0.03 & 0.78 & 1.00 & & & & & & & & & & \\
\hline 5. Boredom (subscale) & -0.03 & 0.04 & 0.79 & 0.55 & 1.00 & & & & & & & & & \\
\hline 6. Adventure (subscale) & 0.02 & -0.04 & 0.79 & 0.44 & 0.45 & 1.00 & & & & & & & & \\
\hline 7. Disinhibition (subscale) & 0.06 & 0.02 & 0.79 & 0.44 & 0.51 & 0.54 & 1.00 & & & & & & & \\
\hline 8. Aggressivity ZKPQ-50-cc & 0.15 & 0.16 & 0.19 & 0.03 & 0.16 & 0.13 & 0.27 & 1.00 & & & & & & \\
\hline 9. Sociability ZKPQ-50-cc & -0.10 & -0.20 & 0.21 & 0.05 & 0.18 & 0.14 & 0.30 & 0.09 & 1.00 & & & & & \\
\hline 10. Anxiety ZKPQ-50-cc & 0.23 & 0.45 & -0.04 & -0.04 & 0.02 & -0.10 & 0.01 & 0.26 & -0.25 & 1.00 & & & & \\
\hline 11. Binge: 6 alcoholic beverages at one sitting & -0.05 & -0.04 & -0.27 & -0.10 & -0.17 & -0.19 & -0.40 & -0.17 & -0.23 & -0.01 & 1.00 & & & \\
\hline 12. Frequency of drinking in days per week & 0.02 & 0.10 & 0.18 & 0.06 & 0.14 & 0.10 & 0.26 & $0-14$ & 0.13 & 0.04 & -0.57 & 1.00 & & \\
\hline 13. Age cannabis use onset & -0.03 & -0.08 & -0.12 & -0.02 & -0.06 & -0.11 & -0.19 & -0.17 & -0.02 & 0 & 0.19 & -0.21 & 1.00 & \\
\hline 14. Age getting "high" on cannabis for the first time & -0.03 & -0.08 & -0.10 & -0.02 & -0.04 & -0.10 & -0.16 & -0.16 & 0.004 & 0.01 & 0.16 & -0.18 & 0.90 & 1.00 \\
\hline
\end{tabular}

consequence of differences in assessment tools, population studied, use of polythetic classification, and proposed cutoffs [12].

The study has a number of strengths, such as the recruitment of a representative sample of young men and a high response rate. This is a possible advantage in consideration of the self-selection bias described in online recruitment-based studies [93]. Another important strength is the inclusion of two different and large linguistic samples. Among the weaknesses of the study are a lack of women in the present samples and a lack of concomitant evaluation of the specific games activities of the participants. Further studies of the GAS may be needed to assess different games and other Internetrelated behaviors.

\section{Conclusion}

The 7-item GAS seems to be an interesting assessment tool. This scale, previously used for adolescent samples, appears to be adequate for adult samples and has good psychometric properties in its French and German versions.

\section{Ethics approval and consent to participate}

The study at hand, issued from the C-SURF research protocol number 15/07, was approved by the Lausanne University Medical School's Ethics Committee for Clinical Research. All participants gave their written informed consent to participate in the study.

\section{Consent for publication}

Not applicable.
Availability of data and materials

Availble upon requesto to the last author Gerhard Gmel: Gerhard.Gmel@chuv.ch.

\section{Additional file}

Additional file 1: Translation of the Game Addiction Scale (DOCX $72 \mathrm{~kb}$ )

\section{Abbreviations}

BSSS: brief sensation seeking scale; CFA: confirmatory factor analysis; CFI: comparative fit index; C-SURF: cohort study on substance use risk factors; DSM-IV: diagnostic statistical manual of mental disorders, fourth edition; EFAs: exploratory factor analyses; GAS: game addiction scale; ICD-10: international classification of mental and behavioral disorders; MAP: velicer's minimum average partial test; MDI: major depression inventory; RMSEA: root mean square error of approximation; SEM: structural equation modeling; ZKPQ-50-cc: ZuckermanKuhlman personality questionnaire.

\section{Competing interests}

The authors declare that they have no competing interests.

\section{Authors' contributions}

GG organized the original investigation and made substantial contributions to conception and design and data acquisition, YK, GG and DZ parin the design of the present paper and made substantial contributions to the conception of the study at hand. YK drafted the manuscript. AC performed the statistical analysis and drafted the manuscript. GG, SR, DZ, SA and GT contributed to helped draft the manuscript. GG, SR, DZ, SA and GT have been involved in revising the manuscript critically for important intellectual contentment. All authors were involved in the interpretation of data, drafting and revising the article. All authors read and approved the final manuscript.

\section{Acknowledgements}

To the funding source.

\section{Funding}

Funding for this study was provided by the Swiss National Science Foundation (FN 33CSC0-122679 and FN 33CS30-139467). 


\section{Author details}

'Department of Mental health and psychiatry, Geneva University Hospitals, Geneva, Switzerland. ${ }^{2}$ Department of psychiatry, Geneva University, Geneva, Switzerland. ${ }^{3}$ Lausanne University, Lausanne, Switzerland.

\section{Received: 1 October 2015 Accepted: 27 April 2016}

\section{Published online: 10 May 2016}

\section{References}

1. Rodda S, Lubman DI, Dowling NA, Bough A, Jackson AC. Web-based counseling for problem gambling: exploring motivations and recommendations. J Med Internet Res. 2013;15(5):e99.

2. Powell J, Hamborg T, Stallard N, Burls A, McSorley J, Bennett K, Griffiths KM, Christensen $\mathrm{H}$. Effectiveness of a web-based cognitive-behavioral tool to improve mental well-being in the general population: randomized controlled trial. J Med Internet Res. 2013;15(1):e2.

3. Bolier L, Haverman M, Kramer J, Westerhof GJ, Riper H, Walburg JA, Boon B, Bohlmeijer E. An Internet-based intervention to promote mental fitness for mildly depressed adults: randomized controlled trial. J Med Internet Res. 2013;15(9):e200

4. Harris $I M$, Roberts $L M$. Exploring the use and effects of deliberate self-harm websites: an internet-based study. J Med Internet Res. 2013;15(12):e285.

5. van Gaalen JL, Beerthuizen T, van der Meer V, van Reisen P, Redelijkheid GW, Snoeck-Stroband JB, Sont JK, Group SS. Long-term outcomes of internet-based self-management support in adults with asthma: randomized controlled trial. J Med Internet Res. 2013;15(9):e188.

6. Ramo DE, Prochaska JJ. Broad reach and targeted recruitment using Facebook for an online survey of young adult substance use. J Med Internet Res. 2012;14(1):e28.

7. Morel V, Chatton A, Cochand S, Zullino D, Khazaal Y. Quality of web-based information on bipolar disorder. J Affect Disord. 2008;110(3):265-9.

8. Khazaal Y, Chatton A, Cochand S, Coquard O, Fernandez S, Khan R, Billieux J, Zullino D. Brief DISCERN, six questions for the evaluation of evidence-based content of health-related websites. Patient Educ Couns. 2009.

9. Monney G, Penzenstadler L, Dupraz O, Etter JF, Khazaal Y. mHealth App for Cannabis Users: Satisfaction and Perceived Usefulness. Frontiers Psychiatry. 2015;6:120.

10. Spada MM. An overview of problematic Internet use. Addict Behav. 2014; 39(1):3-6.

11. Koo C, Wati Y, Lee CC, Oh HY. Internet-addicted kids and South Korean government efforts: boot-camp case. Cyberpsychol Behav Soc Netw. 2011; 14(6):391-4.

12. Kuss DJ, Griffiths MD, Karila L, Billieux J. Internet addiction: a systematic review of epidemiological research for the last decade. Curr Pharm Des. 2014;20(25):4026-52

13. Aboujaoude E. Problematic Internet use: an overview. World Psychiatry. 2010;9(2):85-90.

14. Geisel O, Panneck P, Stickel A, Schneider M, Muller CA. Characteristics of Social Network Gamers: Results of an Online Survey. Frontiers Psychiatry. 2015;6:69

15. Wei HT, Chen MH, Huang PC, Bai YM. The association between online gaming, social phobia, and depression: an internet survey. BMC Psychiatry. 2012;12:92.

16. Zanetta Dauriat F, Zermatten A, Billieux J, Thorens G, Bondolfi G, Zullino D, Khazaal Y. Motivations to play specifically predict excessive involvement in massively multiplayer online role-playing games: evidence from an online survey. Eur Addict Res. 2011:17(4):185-9.

17. Billieux J, Chanal J, Khazaal Y, Rochat L, Gay P, Zullino D, Van der Linden M. Psychological predictors of problematic involvement in massively multiplayer online role-playing games: illustration in a sample of male cybercafe players. Psychopathology. 2011:44(3):165-71.

18. Billieux J, Thorens G, Khazaal Y, Zullino D, Achab S, Van der Linden M. Problematic involvement in online games: A cluster analytic approach. Computers Human Behavior. 2015;43:242-50.

19. Ho RC, Zhang MW, Tsang TY, Toh AH, Pan F, Lu Y, Cheng C, Yip PS, Lam LT, Lai CM et al. The association between internet addiction and psychiatric co-morbidity: a meta-analysis. BMC Psychiatry. 2014;14:183.

20. te Wildt BT, Putzig I, Zedler M, Ohlmeier MD. [nternet dependency as a symptom of depressive mood disorders]. Psychiatr Prax. 2007;34 Suppl 3:S318-322.

21. Carli V, Durkee T, Wasserman D, Hadlaczky G, Despalins R, Kramarz E, Wasserman C, Sarchiapone M, Hoven CW, Brunner R et al. The association between pathological internet use and comorbid psychopathology: a systematic review. Psychopathology. 2013;46(1):1-13.
22. Brand M, Laier C, Young KS. Internet addiction: coping styles, expectancies, and treatment implications. Frontiers Psychology. 2014;5:1256.

23. Ahmadi J, Amiri A, Ghanizadeh A, Khademalhosseini M, Khademalhosseini Z, Gholami Z, Sharifian M. Prevalence of Addiction to the Internet, Computer Games, DVD, and Video and Its Relationship to Anxiety and Depression in a Sample of Iranian High School Students. Iranian J Psychiatry Behav Sciences. 2014;8(2):75-80.

24. Dalbudak E, Evren C. The relationship of Internet addiction severity with Attention Deficit Hyperactivity Disorder symptoms in Turkish University students; impact of personality traits, depression and anxiety. Compr Psychiatry. 2014;55(3):497-503.

25. Lemmens JS, Valkenburg PM, Peter J. Psychosocial causes and consequences of pathological gaming. Computers Human Behavior. 2011;27(1).

26. AJ VANR, Kuss DJ, Griffiths MD, Shorter GW, Schoenmakers MT DVDM. The (co-)occurrence of problematic video gaming, substance use, and psychosocial problems in adolescents. J Behavioral Addictions. 2014;3(3):157-65.

27. van der Aa N, Overbeek G, Engels RC, Scholte RH, Meerkerk GJ, Van den Eijnden RJ. Daily and compulsive internet use and well-being in adolescence: a diathesis-stress model based on big five personality traits. J Youth Adolesc. 2009:38(6):765-76.

28. Cao F, Su L, Liu T, Gao X. The relationship between impulsivity and Internet addiction in a sample of Chinese adolescents. European Psychiatry. 2007;22(7): 466-71.

29. Choi JS, Park SM, Roh MS, Lee JY, Park CB, Hwang JY, Gwak AR, Jung HY. Dysfunctional inhibitory control and impulsivity in Internet addiction. Psychiatry Res. 2014;215(2):424-8.

30. Mok JY, Choi SW, Kim DJ, Choi JS, Lee J, Ahn H, Choi EJ, Song WY. Latent class analysis on internet and smartphone addiction in college students. Neuropsychiatric Disease Treatment. 2014;10:817-28.

31. Muller KW, Beutel ME, Egloff B, Wolfling K. Investigating Risk Factors for Internet Gaming Disorder: A Comparison of Patients with Addictive Gaming Pathological Gamblers and Healthy Controls regarding the Big Five Personality Traits. Eur Addict Res. 2014;20(3):129-36.

32. Heo J, Oh J, Subramanian SV, Kim Y, Kawachi I. Addictive Internet Use among Korean Adolescents: A National Survey. PLoS One. 2014;9(2):e87819.

33. Senormanci O, Senormanci G, Guclu O, Konkan R. Attachment and family functioning in patients with internet addiction. Gen Hosp Psychiatry. 2014; 36(2):203-7.

34. Lam LT, Peng ZW, Mai JC, Jing J. Factors associated with Internet addiction among adolescents. Cyberpsychology Behav. 2009;12(5):551-5.

35. Petry NM, Rehbein F, Gentile DA, Lemmens JS, Rumpf HJ, Mossle T, Bischof $\mathrm{G}$, Tao R, Fung DS, Borges $\mathrm{G}$ et al. An international consensus for assessing internet gaming disorder using the new DSM-5 approach. Addiction. 2014.

36. $\mathrm{Ko} \mathrm{CH}$, Yen JY. The criteria to diagnose internet gaming disorder from causal online gamer. Addiction. 2014;109(9):1411-2.

37. King DL, Haagsma MC, Delfabbro PH, Gradisar M, Griffiths MD. Toward a consensus definition of pathological video-gaming: a systematic review of psychometric assessment tools. Clin Psychol Rev. 2013;33(3):331-42.

38. Petry NM, Rehbein F, Ko CH, O'Brien CP. Internet Gaming Disorder in the DSM-5. Curr Psychiatry Rep. 2015:17(9):72

39. Young KS. The research and controversy surrounding internet addiction. Cyberpsychology Behavior. 1999;2(5):381-3.

40. Demetrovics Z, Urban R, Nagygyorgy K, Farkas J, Griffiths MD, Papay O, Kokonyei G, Felvinczi K, Olah A. The development of the Problematic Online Gaming Questionnaire (POGQ). PLoS One. 2012;7(5):e36417.

41. Lortie $\mathrm{CL}$, Guitton MJ. Internet addiction assessment tools: dimensional structure and methodological status. Addiction. 2013;108(7):1207-16.

42. Khazaal Y, Achab S, Billieux J, Thorens G, Zullino D, Dufour M, Rothen S. Factor Structure of the Internet Addiction Test in Online Gamers and Poker Players. JMIR Mental Health. 2015;2(2):e12.

43. King DL, Delfabbro PH, Griffiths MD. Trajectories of problem video gaming among adult regular gamers: an 18-month longitudinal study. Cyberpsychol Behav Soc Netw. 2013;16(1):72-6.

44. Lemmens JS, Valkenburg PM, Peter J. Development and Validation of a Game Addiction Scale for Adolescents. Media Psychology. 2009;12(1):77-95.

45. van Holst RJ, Lemmens JS, Valkenburg PM, Peter J, Veltman DJ, Goudriaan AE. Attentional bias and disinhibition toward gaming cues are related to problem gaming in male adolescents. J Adolescent Health. 2012:50(6):541-6.

46. Torres A, Catena A, Megias A, Maldonado A, Candido A, Verdejo-Garcia A, Perales JC. Emotional and non-emotional pathways to impulsive behavior and addiction. Front Hum Neurosci. 2013;7:43. 
47. Billieux J, Khazaal Y, Oliveira S, de Timary P, Edel Y, Zebouni F, Zullino D, Van der Linden M. The Geneva Appetitive Alcohol Pictures (GAAP): development and preliminary validation. Eur Addict Res. 2011;17(5):225-30.

48. Khazaal Y, Zullino D, Billieux J. The Geneva Smoking Pictures: development and preliminary validation. Eur Addict Res. 2012;18(3):103-9.

49. Michalczuk R, Bowden-Jones H, Verdejo-Garcia A, Clark L. Impulsivity and cognitive distortions in pathological gamblers attending the UK National Problem Gambling Clinic: a preliminary report. Psychol Med. 2011;41(12): 2625-35.

50. Gaetan S, Bonnet A, Brejard V, Cury F. French validation of the 7-item Game Addiction Scale for adolescents. European Review Applied Psychology. 2014;64(4):161-8.

51. Mohler-Kuo M, Wydler H, Zellweger U, Gutzwiller F. Differences in health status and health behaviour among young Swiss adults between 1993 and 2003. Swiss Med Wkly. 2006;136(29-30):464-72.

52. Studer J, Mohler-Kuo M, Dermota P, Gaume J, Bertholet N, Eidenbenz C, Daeppen JB, Gmel G. Need for informed consent in substance use studiesharm of bias? J Stud Alcohol Drugs. 2013;74(6):931-40.

53. Bech P, Rasmussen NA, Olsen LR, Noerholm V, Abildgaard W. The sensitivity and specificity of the Major Depression Inventory, using the Present State Examination as the index of diagnostic validity. J Affect Disord. 2001;66(2-3): 159-64.

54. Olsen LR, Jensen DV, Noerholm V, Martiny K, Bech P. The internal and external validity of the Major Depression Inventory in measuring severity of depressive states. Psychol Med. 2003;33(2):351-6.

55. Cuijpers P, Dekker J, Noteboom A, Smits N, Peen J. Sensitivity and specificity of the Major Depression Inventory in outpatients. BMC Psychiatry. 2007;7:39.

56. Bech P, Timmerby N, Martiny K, Lunde M, Soendergaard S. Psychometric evaluation of the Major Depression Inventory (MDI) as depression severity scale using the LEAD (Longitudinal Expert Assessment of All Data) as index of validity. BMC Psychiatry. 2015;15:190.

57. Hoyle RH, Stephenson MT, Palmgreen P, Lorch EP, Donohew RL. Reliability and validity of a brief measure of sensation seeking. Personality Individual Differences. 2002;32:401.

58. Aluja A, Rossier J, Garcia LF, Angleitner A, Kuhlman M, Zuckerman M. A cross-cultural shortened form of the ZKPQ (ZKPQ-50-cc) adapted to English, French, German, and Spanish languages. Personality Individual Differences. 2006:41:619-28.

59. Floros G, Siomos K, Stogiannidou A, Giouzepas I, Garyfallos G. The relationship between personality, defense styles, internet addiction disorder and psychopathology in college students. Cyberpsychol Behav Soc Netw. 2014;17(10):672-6.

60. Ritson B, he 1999 ESPAD Report. The European School Survey Project on Alcohol and Other Drug Use among Students in 30 European Countries. By Björn Hibell, Barboro Andersson, Salme Ahlström, Olga Balakireva, Thoroddur Bjarnason, Anna Kokkevi and Mark Morgan. The Swedish Council for Information on Alcohol and Other Drugs, Stockholm. 2000. Alcohol Alcohol. 2003;38(1):99-9.

61. Streiner DL, Norman GR. Health Measurement Scales. Fourthth ed. New York: Oxford Univesity Press; 2008.

62. Velicer WF. Determining the number of components from the matrix of partial correlations. Psychometrika. 1976;41:321-7.

63. O'Connor BP. SPSS and SAS programs for determining the number of components using parallel analysis and Velicer's MAP test. Behav Res Methods Instrumentation Computers. 2000;32:396-402.

64. Joreskog KG. Simultaneous factor analysis in several populations. Psychometrika. 1971;36:409-26.

65. Byrne BM. Structural Equation Modeling with AMOS. 2nd ed. New York: Routledge; 2009

66. Hoyle RH. Handbook of structural equation modeling. New York: The Guilford Press; 2012.

67. Hu LT, Bentler PM. Cutoff criteria for fit indexes in covariance structure analysis: conventional criteria versus new alternatives. Structural Equation Modeling. 1999;6:1-55

68. Cohen J. Statistical power analysis for the behavioral sciences. 2nd ed. New Jersey: 1988

69. Andridge RR, Little RJ. A Review of Hot Deck Imputation for Survey Nonresponse. Int Stat Rev. 2010;78(1):40-64.

70. Myers TA, Mason G. Goodbye, Listwise Deletion: Presenting Hot Deck Imputation as an Easy and Effective Tool for Handling Missing Data. Communication Methods Measures. 2011;5(4):297-310.
71. Bentler PM, Chou C-P. Practical Issues in Structural Modeling. Sociological Methods and Res. 1987;16:78-117.

72. Kline R. Principles and practice of structural equation modeling. 3rd ed. New York London: The Guilford Press; 2011.

73. Byrne BM. Testing for multigroup invariance using AMOS graphics: a road less traveled. Structural Equation Modeling. 2004;11(2):272-300.

74. Montag C, Bey K, Sha P, Li M, Chen YF, Liu WY, Zhu YK, Li CB, Markett S, Keiper J, et al. Is it meaningful to distinguish between generalized and specific Internet addiction? Evidence from a cross-cultural study from Germany, Sweden, Taiwan and China. Asia-Pacific Psychiatry. 2014.

75. Kiraly O, Griffiths MD, Urban R, Farkas J, Kokonyei G, Elekes Z, Tamas D, Demetrovics Z. Problematic internet use and problematic online gaming are not the same: findings from a large nationally representative adolescent sample. Cyberpsychol Behav Soc Netw. 2014;17(12):749-54.

76. Yang L, Sun L, Zhang Z, Sun Y, Wu H, Ye D. Internet addiction, adolescent depression, and the mediating role of life events: finding from a sample of Chinese adolescents. Int J Psychology. 2014;49(5):342-7.

77. Valero S, Daigre C, Rodriguez-Cintas L, Barral C, Goma IFM, Ferrer M, Casas M, Roncero C. Neuroticism and impulsivity: their hierarchical organization in the personality characterization of drug-dependent patients from a decision tree learning perspective. Compr Psychiatry. 2014;55(5):1227-33.

78. Roncero C, Daigre C, Barral C, Ros-Cucurull E, Grau-Lopez L, RodriguezCintas L, Tarifa N, Casas M, Valero S. Neuroticism associated with cocaineinduced psychosis in cocaine-dependent patients: a cross-sectional observational study. PLoS One. 2014;9(9):e106111.

79. Kumar $\mathrm{P}$, Singh U. Internet Addiction in Relation to Personality Factors of Zuckerman's Alternative Five Factor Model. Indian J Health Wellbeing. 2014; 5(4):500-2.

80. Kowert R, Domahidi E, Quandt T. The relationship between online video game involvement and gaming-related friendships among emotionally sensitive individuals. Cyberpsychol Behav Soc Netw. 2014;17(7):447-53.

81. Mehroof M, Griffiths MD. Online gaming addiction: the role of sensation seeking, self-control, neuroticism, aggression, state anxiety, and trait anxiety. Cyberpsychol Behav Soc Netw. 2010;13(3):313-6.

82. Kuss DJ, Louws J, Wiers RW. Online gaming addiction? Motives predict addictive play behavior in massively multiplayer online role-playing games. Cyberpsychol Behav Soc Netw. 2012;15(9):480-5.

83. Yen JY, Ko CH, Yen CF, Chen CS, Chen CC. The association between harmful alcohol use and Internet addiction among college students: comparison of personality. Psychiatry Clin Neurosci. 2009;63(2):218-24

84. Kuss DJ, Griffiths MD, Binder JF. Internet addiction in students: Prevalence and risk factors. Computers Human Behavior. 2013;29(3):959-66.

85. Khazaal Y, Chatton A, Horn A, Achab S, Thorens G, Zullino D, Billieux J. French Validation of the Compulsive Internet Use Scale (CIUS). Psychiatry Q. 2012.

86. Khazaal Y, Billieux J, Thorens G, Khan R, Louati Y, Scarlatti E, Theintz F, Lederrey J, Van Der Linden $M$, Zullino D. French validation of the internet addiction test. Cyberpsychology Behavior. 2008;11(6):703-6.

87. Johansson A, Gotestam KG. Internet addiction: characteristics of a questionnaire and prevalence in Norwegian youth (12-18 years). Scand J Psychol. 2004:45(3):223-9.

88. Kaltiala-Heino R, Lintonen T, Rimpelä A. Internet addiction? Potentially problematic use of the Internet in a population of 12-18 year-old adolescents. Addiction ResTheory. 2004;12(1):89-96.

89. Durkee T, Kaess M, Carli V, Parzer P, Wasserman C, Floderus B, Apter A, Balazs J, Barzilay S, Bobes J, et al. Prevalence of pathological internet use among adolescents in Europe: demographic and social factors. Addiction. 2012:107(12):2210-22.

90. Haagsma MC, Pieterse ME, Peters $\mathrm{O}$. The prevalence of problematic video gamers in the Netherlands. Cyberpsychol Behav Soc Netw. 2012;15(3):162-8.

91. Van Rooij AJ, Schoenmakers TM, Vermulst AA, Van den Eijnden RJ, Van de Mheen D. Online video game addiction: identification of addicted adolescent gamers. Addiction. 2011;106(1):205-12.

92. Xu J, Shen LX, Yan CH, Wu ZQ, Ma ZZ, Jin XM, Shen XM. [Internet addiction among Shanghai adolescents: prevalence and epidemiological features]. Zhonghua yu fang yi xue za zhi. 2008:42(10):735-8.

93. Khazaal $Y$, van Singer $M$, Chatton A, Achab $S$, Zullino D, Rothen $S$, Khan $R$, Billieux J, Thorens G. Does self-selection affect samples' representativeness in online surveys? An investigation in online video game research. J Med Internet Res. 2014;16(7):e164. 